\title{
THE OPTIMIZATION ON THE VIATICAL INSURANCE MARKET*
}

ŚLĄSKI

PRZEGLACD

STATYSTYCZNY

Nr 18(24)

ISSN 1644-6739

e-ISSN 2449-9765

\section{Stanisław Heilpern, Joanna Dębicka}

Wroclaw University of Economics and Business, Poland

e-mails: stanislaw.heilpern@ue.wroc.pl; joanna.debicka@ue.wroc.pl

(C) 2020 Stanisław Heilpern, Joanna Dębicka

This work is licensed under the Creative Commons Attribution-ShareAlike 4.0 International License. To view a copy of this license, visit http://creativecommons.org/licenses/by-sa/4.0/

Quote as: Heilpern, S., and Dębicka, J. (2020). The optimization on the viatical insurance market. Śląski Przeglad Statystyczny, 18(24).

DOI: $10.15611 /$ sps.2020.18.15

JEL Classification: D81, G22, G120, C41

We assume that an $x$-year old man has whole-life insurance. In the insurance period, he becomes terminally ill and wants to resell the rights to the death benefit. The insured considers the possibility of reselling only part $\alpha$ of the rights to death benefit $c$. If he resells his right to the policy, he receives the viatical settlement payment (VSP) from the investor. The policyholder is obliged to pay annual premiums $p$ at the beginning of each year of the insurance period. He would like to choose $\alpha$ for the maximum benefit from his point of view. The paper considered the above optimization problem which is due to the insured's behaviour under risky conditions and the value of VSP.

To model viatical contracts, the authors used the multiple state model introduced by Dębicka and Heilpern in [Dębicka, Heilpern 2017], which consists of the space of each state $S=\{1,2, \ldots, 5\}$ for the following five states:

1 - the insured is terminally ill and his expected lifetime is less than 4 years.

2 - the insured is terminally ill and his expected lifetime is less than 3 years.

3 - the insured is terminally ill and his expected lifetime is less than 2 years.

4 - the insured is terminally ill and his expected lifetime is less than 1 year.

5 - the insured died being terminally ill with a fatal disease.

*25th Scientific Statistical Seminar „Marburg-Wrocław”. Gollhofen, 23-26 September 2019. Extended abstract. 
Let $X$ be the random variable describing the total cash flows after resale policy. The distribution of random variable $X$ takes the following form:

$$
P\left(X=x_{k}\right)=q_{k},
$$

where $k=1,2,3,4, q_{1}=1-p_{12}, q_{2}=p_{12}\left(1-p_{23}\right), q_{3}=p_{12} p_{23}\left(1-p_{34}\right), q_{4}=$ $p_{12} p_{23} p_{34}$, and $p_{i j}$ are the transition probability from state $i$ to state $j$. The values $x_{k}$ of the cash flow equal $x_{k}=\alpha V S P+(1-\alpha) b_{k}$, where $b_{k}=v^{k} c-p \sum_{i=0}^{k-1} v^{i}$.

The expected value of this cash flow is

$$
E X=\sum_{k=1}^{4} x_{k} q_{k}=\alpha V S P+(1-\alpha) \sum_{k=1}^{4} b_{k} q_{k} .
$$

If $V S P<\sum_{k=1}^{4} b_{k} q_{k}$, then we obtain a maximum of $E X$ when $\alpha=0$. For $V S P>\sum_{k=1}^{4} b_{k} q_{k}$ we have maximum when $\alpha=1$, and for $V S P=\sum_{k=1}^{4} b_{k} q_{k}$ all $\alpha$ 's are just as 'good'.

Now let us take into consideration different kinds of behaviour of the insured under risky conditions. When the insured follows the utility theory [von Neumann, Morgenstern 1944], then he maximizes the expected utility of cash flow:

$$
E(U(X))=\sum_{k=1}^{4} U\left(x_{k}\right) q_{k},
$$

where $U(x)$ is a utility function. We use the discounted utility model (Hey 2004) and obtain

$$
U\left(x_{k}\right)=u(\alpha V S P-(1-\alpha) p)+u((\alpha-1) p) \sum_{i=1}^{k-1} v^{i}+u((1-\alpha) c) v^{k}
$$

where $u$ is continuous, concave (risk aversion), increasing function, such that $u(0)=0$. When the utility function has the power form:

$$
u_{1}(x)=(x+p)^{\beta}-p^{\beta},
$$

we obtain the maximum of $E(U(X))$ for

$$
\alpha_{0}=\frac{\left(c A_{c}\right)^{1 /(\beta-1)}(c+p)}{\left((V S P+p)^{\beta}+p^{\beta} A_{p}\right)^{1 /(\beta-1)}+c^{\beta /(\beta-1)} A_{c}^{1 /(\beta-1)}},
$$


where $A_{p}=\sum_{k=2}^{4}\left(\sum_{i=1}^{k-1} v^{i}\right) q_{k}$ and $A_{c}=\sum_{k=1}^{4} v^{k} q_{k}$.

The rank dependent expected utility (RDEU) theory [Quiggin 1982] is based on the Choquet integral, the utility function $u(x)$ and distorted probability function $w(q)$, where $w:[0,1] \rightarrow[0,1]$ is increasing and $w(0)$ $=0, w(1)=1$. The RDEU is

$$
E_{w}(u(X))=\int_{0}^{\infty} w(S(x)) d x-\int_{-\infty}^{0}(1-w(S(x))) d x=\sum_{k=1}^{4} u\left(x_{k}\right) w_{k},
$$

where $S(x)$ is the survival function of random variable $Y=u(X), w_{1}=w\left(q_{1}\right)$, $w_{2}=w\left(q_{1}+q_{2}\right)-w\left(q_{1}\right), w_{3}=w\left(1-q_{4}\right)-w\left(q_{1}+q_{2}\right)$ and $w_{4}=1-w\left(1-q_{4}\right)$. We obtain a similar situation as in the usual utility theory; only the probabilities are distorted.

The insured, who follows the cumulative prospect theory [Tversky, Kahneman 1992] maximizes the generalized expected utility

$$
E_{w_{+}, w_{-}}(u(X))=\int_{0}^{\infty} w_{+}(S(x)) d x-\int_{-\infty}^{0} w_{-}(F(x)) d x,
$$

where $F(x)$ is a cumulative distribution function of $Y$. Yet in this case the values of the cash flow $x_{k}>0$, then we use the distorted probabilities $w_{+. k}$ only. The authors in [Kahneman, Tversky 1979] proposed the utility function

$$
u_{2}(x)=\left\{\begin{array}{cc}
x^{\beta} & x \geq 0 \\
-\lambda(-x)^{\beta} & x<0
\end{array},\right.
$$

where $\beta=0.88$ and $\lambda=2.25$ and the distorted function

$$
w(q)=\frac{q^{\gamma}}{\left(q^{\gamma}+(1-q)^{\gamma}\right)^{1 / \gamma}},
$$

where $\gamma_{+}=0.61$ and $\gamma_{-}=0.69$. If the insured follows the cumulative prospect theory, the expected utility of the cash flow takes the following form

$$
E_{w+}(U(X))=\left\{\begin{array}{cc}
(\alpha V S P-(1-\alpha) p)^{\beta}+(1-\alpha)^{\beta} B & \alpha \geq \alpha_{V} \\
(1-\alpha)^{\beta} B-\lambda((1-\alpha) p-\alpha V S P)^{\beta} & \alpha<\alpha_{V}
\end{array},\right.
$$


where $\quad \alpha_{V}=\frac{p}{V S P+p}, \quad B=A_{c} c^{\beta}-\lambda A_{p} p^{\beta}, \quad A_{p}=\sum_{k=2}^{4}\left(\sum_{i=1}^{k-1} v^{i}\right) w_{+, k} \quad$ and $A_{c}=\sum_{k=1}^{4} v^{k} w_{+, k}$. The maximum value of the expected utility of the cash flow can be at points $\alpha=0$ or $\frac{p(V S P+p)^{1 /(\beta-1)}+B^{1 /(\beta-1)}}{(V S P+p)^{\beta /(\beta-1)}+B^{1 /(\beta-1)}}$ when $\alpha \geq \alpha_{V}$ and at $\alpha=0$ or $\frac{B^{1 /(\beta-1)}-p(V S P+p)^{1 /(\beta-1)}}{B^{1 /(\beta-1)}-\lambda^{1 /(\beta-1)}(V S P+p)^{\beta /(\beta-1)}}$ when $\alpha<\alpha_{V}$

Example. A 60-year man fell ill, he established a policy at $x=20$ years. Let $c=100, p=0,013 c$ and $v=0.98$. Then $59.200<V S P<96.899$.

A. Thus $E(X)=\alpha V S P+95.687(1-\alpha)$. Therefore, for $V S P<95.914$, $\alpha=0$ guarantees the maximal value of $E(X)$ and for $V S P>95.687$ we have $\alpha=1$; but for $V S P=95.687$, every $0 \leq \alpha \leq 1$ is just as 'good'.

B. For power utility function $u_{1}(x)$ and $\beta=0.6$ we obtain

$$
\begin{gathered}
E(U(X))=\left((V S P+1.4817)^{0.6}+0.3201\right) \alpha^{0.6}+ \\
0.9754(101.4817-100 \alpha)^{0.6}-2.8211
\end{gathered}
$$

and we have a maximum of $E(U(X))$ for

$$
\alpha_{0}=\frac{0.001080}{\left((V S P+1.4817)^{0.6}+0.3201\right)^{-2.5}+0.001064} \text {. The greater values of }
$$

$V S P$ imply a greater value of the optimal parameter $\alpha$.

C. We use the utility function $u_{1}(x)$ with $\beta=0.6$ and the distortion probability function $w(q)$ with $\gamma=0.61$ and obtain the RDEU of cash flow

$$
\begin{gathered}
E_{w}(U(X))=\left((V S P+1.4817)^{0.6}+0.8476\right) \alpha^{0.6}+ \\
0.9673(101.4817-100 \alpha)^{0.6}-3.3383 .
\end{gathered}
$$

The maximum of $E_{w}(U(X))$ is reached at point $\alpha_{0}=\frac{0.001071}{\left((V S P+1.4817)^{0.6}+0.8476\right)^{-2.5}+0.001087} \quad$ We obtain similar

results as in b), but we obtain the greater values of the optimal $\alpha_{0}$ and smaller values of the expected utility of the cash flow.

D. For utility function $u_{2}(x)$ with $\beta=0.88, \lambda=2.25$ and the distorted probability function $w(q)$ with $\gamma_{+}=0.61$ the expected utility of the cash flow is 
$E(U(X))=\left\{\begin{array}{ll}(\alpha V S P-1.4817(1-\alpha))^{0.88}+53.5312(1-\alpha)^{0.88} & \alpha \geq \alpha_{V} \\ 53.5312(1-\alpha)^{0.88}-2.25(1.4817(1-\alpha)-\alpha V S P)^{0.88} & \alpha<\alpha_{V}\end{array}, \begin{array}{l}\text { PRZEGLAD } \\ \text { STATYSTYCZNY }\end{array}\right.$

where $\alpha_{V}=\frac{1.4817}{V S P+1.4817}$. When $x=20$ for acceptable values of $V S P$, we obtain similar results to the classic utility case, but for $x=55$, we have $14.254<V S P<93.482$ and we observe a different situation. For $V S P \leq$ 20.556 the optimal value $\alpha_{0}=0$. The graph of the values of optimal $\alpha$ with respect to VSP is not continuous in point $V S P=19.475$. The greater values of $\lambda$, reflecting the insured's approach to losses, imply a greater value of the optimal parameter $\alpha$.

Proof of the presented results and more examples can be found in [Dębicka, Heilpern 2020].

\section{Acknowledgements}

The support of the grant scheme NON-STANDARD MULTILIFE INSURANCE PRODUCTS WITH DEPENDENCE BETWEEN INSURED 2013/09/B/HS4/00490 is gratefully acknowledged.

\section{References}

Dębicka J., Heilpern S., 2017, Investor's expected profit from viatical settlement. 20th AMSE. Applications of Mathematics in Economics. International Scientific Conference: International Scientific Conference: Szklarska Poręba, Poland, 30 Aug-3 Sept 2017. Conference Proceedings.

Dębicka J., Heilpern S., 2020, The optimization of insurance contracts on the viatical market - in press.

Hey J.D., 2004, Intermediate Microeconomics: People are Different, McGraw-Hill, London.

Kahneman D., Tversky A., 1979, Prospect theory: An analysis of decision under risk, Econometrica, 47, pp. 313-327.

Quiggin J., 1982, A theory of anticipated utility, Journal of Economic Behavior and Organization, vol. 3, pp. 323-343.

Tversky A., Kahneman D., 1992, Advances in prospect theory: cumulative representation of uncertainty, Journal of Risk and Uncertainty, vol. 5, pp. 297-323.

von Neumann J., Morgenstern O., 1944, Theory of Games and Economic Behavior, Princeton University Press, Princeton.

Keywords: viatical settlement, multistate model, Bernoulli principle, Rank Dependent Expected Utility Theory, Cumulative Prospect Theory. 